\title{
Using the HOS Method for Evaluating the Efficiency of Environmental Information Systems
}

\author{
Zuzana Chvátalová and Miloš Koch \\ Brno University of Technology, Faculty of Business and Management, \\ Kolejni 4, 61200 Brno, Czech Republic \\ \{koch, chvatalova\}@fbm.vutbr.cz
}

\begin{abstract}
In this paper the authors apply the principles of the HOS method developed at the Faculty of Business and Management at the Brno University of Technology for evaluating the efficiency of information systems including environmental information system (EIS). Selected results of the authors' research based on monitoring more than four hundred organizations are presented in a case study. The authors also take into account some aspects of the formulation of environmental information of the Czech Republic (supported by, e.g., the Czech Statistical Office). The primary principle of the research is to determine the level of balance of the organization's information system, this being the key prerequisite of its effectiveness. The effectiveness is understood as maximizing the output with respect to minimizing the total cost. It is a way of implementing information and communication technologies and respecting their characteristics as properties of the information system generally and within the limits of sustainability of their development and implementation throughout their life cycle. Organizations respecting these rules support the use of the tools and stateof-the-art environmental informatics, and thus significantly contribute to their sustainable development.
\end{abstract}

Keywords: Balance, Czech Statistical Office, Efficiency and Effectiveness, Environmental Information Systems, Evaluation, HOS Method and HOS Diagram, Information System, Statistics, Subsystem.

\section{Introduction}

Since 1990, informatics, information systems (IS) and information and communication technologies (ICT) in the Czech Republic (CZ) have become an important developmental post-revolutionary phenomenon. Since the end of the 1990s when the first concept of state information policy was formed, other information systems in state administration, institutions and business units have been developed and thus CZ informatics has been integrated into world and European structures.

Hřebíček and Kubásek [5] have said about the situation in CZ: "After 1990 there has been a big expansion of information and communication technologies, which has resulted in increased access to the growing amount of data and information through the Internet and Web services. In the creation and protection of the environment there 
are many projects in the private and public spheres (businesses, institutions, public authorities and non-governmental organizations), which are being used to collect environmental data and information and also for providing information services concerning the environment."

Until approximately the 1980s we may assume that the "criteria of success" (efficiency, or rather, effectiveness) of implementing and using an IS were, above all, reaching the pre-determined goal, i.e., a concrete task, for example calculation, graphic output, simulation in a reasonable time-frame, etc. Economic and organizational difficulty, operational literacy, leading the processes, safety or dataaccessibility may have been very disadvantageous all the while and not always effective.

Hamilton and Chervany wrote in [4]: "Evaluations of Management Information Systems (MIS) tend to be subjective and are influenced by the perceptions of system objectives, as well as the experiences with system performance in accomplishing organizational objectives. Consequently, the assessments of MIS effectiveness are often controversial and can be sources of disagreement and conflict between different functional groups involved in MIS implementation - users, MIS development, internal audit, and top management personnel."

The Chairwoman of the Czech Statistical Office (CZSO) professor Ritschelová, et al, wrote [13] about public environmental data, information and statistics: "One of the very important aims of the Czech Statistical Office is to produce, among others, national statistical data on environmental development. During the last two decades one could trace the constantly increasing interest in and attention given to environmental statistics both at the international, national and regional levels." The primary environmental data and information are monitored and collected for the CZSO through the organizations' IS. CZSO also devotes considerable attention to the monitoring of many aspects of the development of ICT and IS in CZ.

Given the growing importance of ICT and their enormous impact on the economy, society and the environment from approximately the beginning of the $21^{\text {th }}$ century, the CZSO has been dealing with statistical monitoring, analysis of the spectrum of ICT and the publication of collected information which provide information to government authorities, organizations, business entities and the public. It carries out extensive research - Information Society, Information Economy, Information Technologies (Information Society in Figures, Use of ICT in the Public Administration Sector, Use of ICT in Households, Use of ICT in Enterprises of the CZ, etc.), more in [1].

The ICT have changed the availability and use of information everywhere. They contribute to changes in laboratory productivity, patterns of resource use, the life of society and the environment.

The emphasis on the importance of current trends of corporate performance evaluation and corporate reporting in the $\mathrm{CZ}$ is discussed in detail in [6], [7], [8]. Corporate reporting requires monitoring (measurement of) the parameters / variables using quantitative and qualitative methods, and advanced mathematical or statistical methods and models as in [9], [10] implemented through efficient ICT tools as in [3].

It is necessary to measure the balance level of the corporate reporting IS - a key assumption of the effectiveness of its complex IS. The effectiveness is understood as 
maximizing the output with respect to minimizing the total cost connected with the IS. Corporations can benefit from a comprehensive approach to implementing their ICTs. Being aware of the characteristics of the ICTs as also being general properties of the IS will also be beneficial. The organisation's overall sustainable development will impose limits on the IS throughout its life cycle. Organizations that respect these facts support the use of the ICT tools, taking into account state-of-the-art environmental informatics, and thus they significantly contribute to their own sustainable development.

Our outcomes of measuring IS efficiency are based primarily on the practical applications of the HOS method for many organizations. The discussed results obtained through the Zefis portal [11] are visualized using Microsoft Excel office applications and some values in the paper are calculated using the Maple system [9-10].

\section{HOS Analysis: Methodology}

HOS analysis is a method used by organizations for the purposes of assessment and investment in IS, or for the modification of IS management strategies using the Zefis portal [11]. The HOS method classifies IS and organizations for their managers and allows them to act, if the efficiency of IS is sufficient, or to see whether the IS should be improved, and in what areas (subsystems), more in [12]. The following formal descriptions are analogous to [12].

\subsection{HOS Analysis: Principle}

The information system $I S$ is composed of individual subsystems $S_{i}, i=1, \ldots, 8$ (also can be called components, parts, elements, areas, etc.), see Table 1.

Table 1. The subsystems in the HOS method (Source: Authors' elaboration, [11], [12])

\begin{tabular}{cccccc}
\hline \multicolumn{7}{c}{ SUBSYSTEMS } \\
\hline Abbreviation & Level & Subsystem & Abbreviation & Level & Subsystem \\
\hline $\mathrm{HW}$ & $L_{1}$ & Hardware & $\mathrm{DW}$ & $L_{5}$ & Dataware \\
\hline $\mathrm{SW}$ & $L_{2}$ & Software & $\mathrm{CU}$ & $L_{6}$ & Customers \\
\hline $\mathrm{OW}$ & $L_{3}$ & Orgware & $\mathrm{SU}$ & $L_{7}$ & Suppliers \\
\hline $\mathrm{PW}$ & $L_{4}$ & Peopleware & MA & $L_{8}$ & Management \\
& & & & & \\
\hline
\end{tabular}

- Subsystem levels $L_{i}, i=1, \ldots, 8$ of the information system $I S$, where the level $L_{i}$ is for the subsystem $S_{i},(i=1, \ldots, 8)$. Each subsystem is rated on a four-point scale as 1 - bad, 2 - somewhat bad, 3 - somewhat good, 4 - good. The assessment of each subsystem can be made by qualified assessment specialists (but this excludes the 
use of methods for the initial assessment by organizations themselves), or using control questions for each subsystem in a questionnaire, [2], [11], [12].

- A overall level $L_{w}$ of the $I S$ (where $1 \leqq m \leqq 8$ for $\forall i, j \in\{1, \ldots, m\}, i \neq j: L_{i} \neq L_{j}$ ) is equal to:

$$
L_{w}=\min \left\{L_{1}, \ldots, L_{m}\right\}
$$

- The definition of a balanced IS, unbalanced IS or heavily unbalanced IS is given in Table 2.

Table 2. The definition of a balanced / unbalanced / heavily unbalanced IS ${ }^{1}$ (Source: Authors' elaboration, [11])

INFORMATION SYSTEM

Balanced

Unbalanced

\section{CONDITIONS}

$$
\left[\sum_{i=1}^{8}\left(L_{i}-L_{w}\right) \leq 3\right] \wedge\left[\forall i \in\{1, . ., 8\}: L_{i}-L_{w} \leq 1\right]
$$

$$
\left[\sum_{i=1}^{8}\left(L_{i}-L_{w}\right)>3\right] \wedge\left[\forall i \in\{1, . ., 8\}: L_{i}-L_{w} \leq 1\right]
$$

$$
\exists i \in\{1, \ldots, 8\}: L_{i}-L_{w}>1
$$

- A recommended level is based on the importance which an organization attaches to the IS.

\subsection{Application of HOS Analysis in an Individual Organization}

As an example of our research, we have selected a Czech manufacturing organization with 145 employees. This is a case of an enterprise information system of a monitored organization that leads to environmental reporting. The CZSO and the Ministry of the Environment (MoE) of the $\mathrm{CZ}$ require obligatory annual reporting (waste, air quality, integrated pollution register, etc.). These subsystems of the enterprise information system (ERP) support these reporting outputs to CZSO and MoE as the organization's environmental information subsystems.

We have used the HOS method for evaluating the organization's IS as follows:

- An assessment of each subsystem of the monitored IS has been made by a qualified assessment specialist and is shown in Table 3.

- In Table 4 we implement all the incremental steps of the HOS method.

${ }^{1}$ Note: In (2), (3), (4) for $\forall i \in\{1, . ., 8\}: 0 \leq L_{i}-L_{w} \leq 3$. 
Table 3. The subsystem levels of the monitored IS (Source: Authors' elaboration, [11])

\begin{tabular}{lcccccccc}
\hline SUBSYSTEMS & HW & SW & OW & PW & DW & CU & SU & MA \\
\hline Level & $\boldsymbol{L}_{\boldsymbol{1}}$ & $\boldsymbol{L}_{\mathbf{2}}$ & $\boldsymbol{L}_{\mathbf{3}}$ & $\boldsymbol{L}_{\mathbf{4}}$ & $\boldsymbol{L}_{5}$ & $\boldsymbol{L}_{\boldsymbol{6}}$ & $\boldsymbol{L}_{\boldsymbol{7}}$ & $\boldsymbol{L}_{\boldsymbol{8}}$ \\
\hline & 3 & 2 & 4 & 2 & 2 & 2 & 3 & 2 \\
\hline
\end{tabular}

Table 4. An evaluation of the IS using the HOS method (Source: Authors' elaboration, [11])

\begin{tabular}{|c|c|c|c|}
\hline \multicolumn{4}{|c|}{$\begin{array}{r}\text { HOS METHOD } \\
\end{array}$} \\
\hline & HOS DIAGRAM & CONDITIONS & IS \\
\hline $\begin{array}{l}\text { Subsystems } \\
\text { Level }\end{array}$ & $\begin{array}{l}\text { Light grey irregular } \\
\text { octagon boundary }\end{array}$ & -- & -- \\
\hline Overall Level & $\begin{array}{l}\text { Grey regular octa- } \\
\text { gon boundary }\end{array}$ & $L_{w}=\min \{4,3,2\}=2$ & 2 \\
\hline $\begin{array}{l}\text { Current } \\
\text { Status }\end{array}$ & & $\begin{array}{c}(4) \\
\sum_{i=1}^{8}\left(L_{i}-2_{w}\right)=4>3 \\
\exists i=3: L_{3}-2=2>1\end{array}$ & $\begin{array}{l}\text { Heavily un- } \\
\text { balanced }\end{array}$ \\
\hline $\begin{array}{l}\text { Recommended } \\
\text { Level }\end{array}$ & $\begin{array}{l}\text { Bold black regular } \\
\text { octagon boundary }\end{array}$ & $\begin{array}{l}\text { The recommended level } \\
\text { is based on the impor- } \\
\text { tance which an organiza- } \\
\text { tion attaches to the IS. }\end{array}$ & $\begin{array}{l}\quad 3 \\
\quad \begin{array}{l}\text { Somewhat } \\
\text { good }\end{array}\end{array}$ \\
\hline
\end{tabular}

- In Figure 1 we make use of all the facts obtained for the visualization of the HOS diagram.

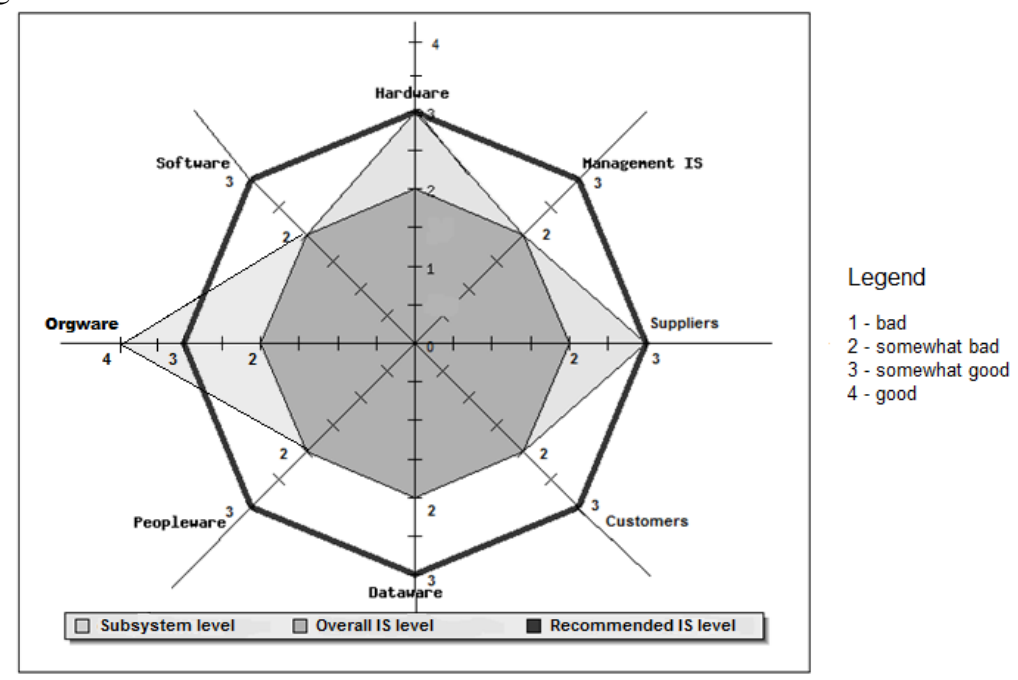

Fig. 1. The HOS diagram corresponding with Table 4 (Source: Authors' elaboration, [11]) 
Results and discussion: The IS of the monitored organization has an overall level equal to 2. Two subsystems (HW, SU) have levels equal to 3, one subsystem (OW) has a level equal to 4 , i.e., differing from the overall level by more than 1 evaluation point. Thus (4) is valid. Therefore the IS is heavily unbalanced. Its recommended level is equal to 3 (somewhat good).

HW: The level of the technical equipment (hardware products such as HW for environmental data collection and emissions measurement, sensors for identifying the sources of pollution, noise, registration of hazardous waste, energy burden, etc.) of this organization is somewhat good.

SU: It is clear that this monitored organization has quite a good level of the sophisticated supply-chain system (i.e., a set of external organizations), i.e., organizations that provide operations and support of the IS on a level that is somewhat good.

OW: It is remarkable that this organization was able to develop good quality rules for the operation of information systems, recommended operating procedures, and security rules. Orgware is evaluated as good.

Other subsystems are assessed as somewhat bad. (For example, the software has a significant disparity between the system and the application subsystems.)

These large disparities of the assessment of the ERP subsystems lead to an overall categorization of "heavily unbalanced IS."

Due to the outputs of the HOS methods and the recommendation of an expert to evaluate the level as somewhat good, we can say that we are dealing with an IS here that has the potential to improve its quality.

\section{Case Study: Selected Aggregated Research Results}

\subsection{The Zefis Portal as a Research Source}

The Zefis portal [11] offers organizations (free of charge, anonymously) the advantage of evaluating the efficiency and balance of the IS using the HOS method (by means of questionnaires). A registered user can carry out surveys and get results immediately. The results can be compared with references in the Zefis databases. The languages of this portal are Czech and English. Many of its users are from Slovakia.

The HOS method was initially designed for the three subsystems (hardware, orgware, software), and the user database had contained more than 2,000 users. In 2010 , the method was modified to include the eight abovementioned areas (subsystems), see third paragraph. At present, our research of IS efficiency deals with and analyses the most current facts and data through the Zefis database.

Currently, the HOS method has been tested on a sample of 425 organizations from the Czech and Slovak Republics in the period from 2010 up until now (as at March 4, 2013).

Although our results reflect a stricter classification, we will respect the general category (in particular, supported by the activities of CZSO) in this paper.

- For the purposes of comparison with the EU, the CZSO regularly presents statistics on the $\mathrm{CZ}$ information society in the following areas: ICT Infrastructure; Households; Individuals; Enterprises; Public Authorities; Schools; Health Establishments. Note: we have merged Households with Individuals into the category 
Others. The representation of the abovementioned groups in our survey sample is presented in Figure 2.

- We will also respect the categorization of organizations according to the number of staff as given by the CZSO: $10-49 ; 50-249 ; 250$ and more. Note: We will include the category of number of staff: $1-9$. The representation of the mentioned groups in our survey sample is presented in Figure 3.

- Note: For the purposes of greater of clarity in this paper, we have rounded to the next integer of percentage.

Comment: Based on Figure 2, we can say that the IS evaluation is mainly interesting for enterprises, namely (on a deeper analysis): commercial and manufacturing, with services and financial services. In terms of their number of staff, enterprises are represented quite equally (see Figure 3). It is interesting that even micro-enterprises are represented comparably.

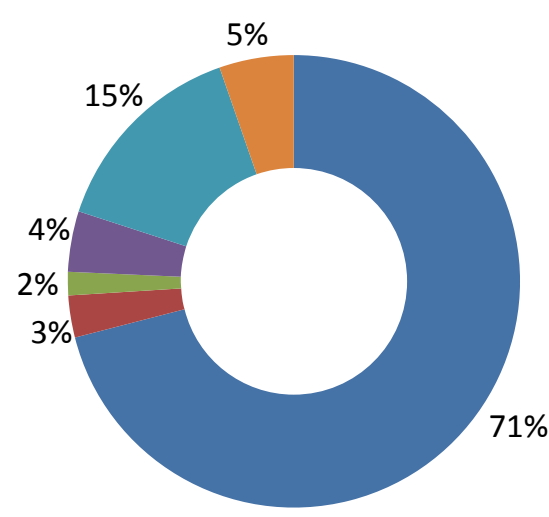

Enterprises

- Public Administration

Health Establishments

Education

ICT Infrastructure

Others

Fig. 2. The information society in our survey - the representation in \% (Source: Authors' elaboration according to [11] in Microsoft Excel)

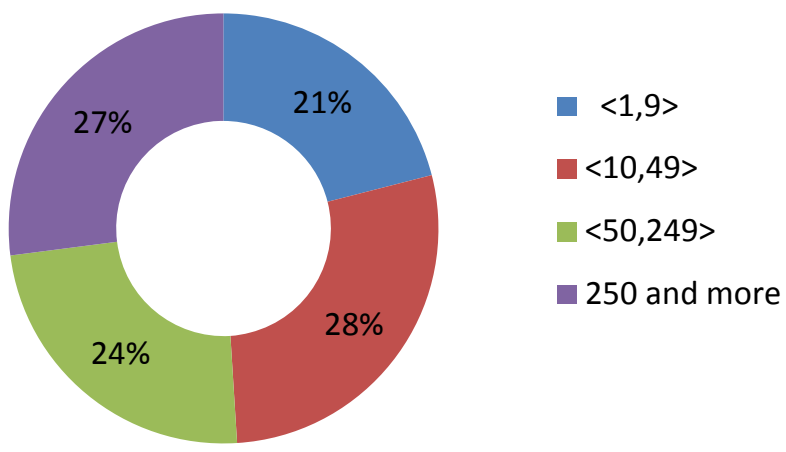

Fig. 3. Numbers of staff in \% (Source: Authors' elaboration according to [11] in Microsoft Excel) 


\subsection{Aggregated Average Research Results}

Here we present the selected aggregated average results of the 425 monitored organizations. For the purpose of IS evaluation using HOS analysis, we have employed the Zefis portal (in the reporting period stated above, see 3.1). The average subsystem levels are represented by a light grey irregular octagon boundary and the average overall level is represented by a grey regular octagon boundary, see Figure 4.

Tables 5 and 6 present the aggregate values (average) of subsystem levels, and the overall and recommended levels (plotted on the individual axes), as well as the corresponding simple statistical diagnostics of the obtained results (variances, standard deviations).

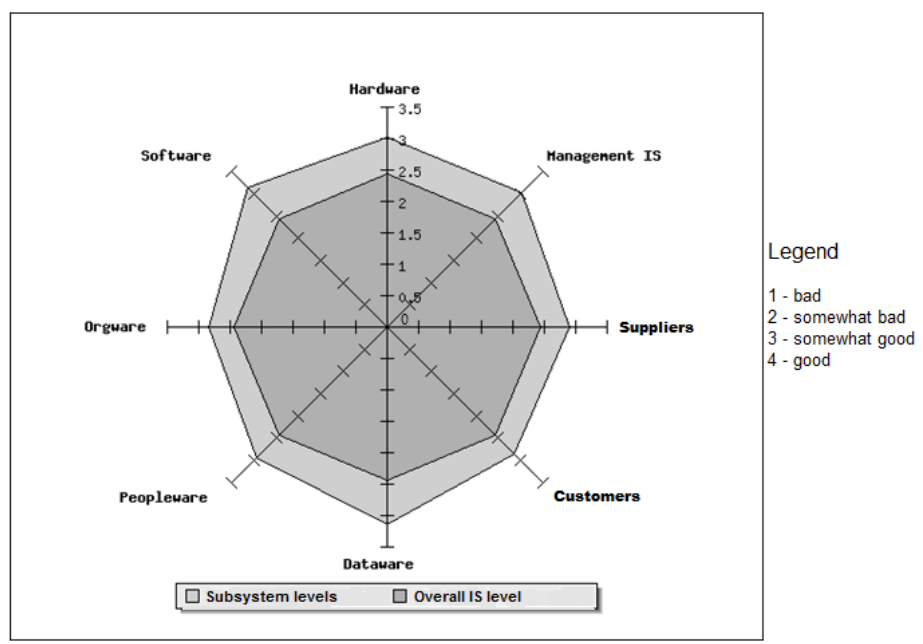

Fig. 4. The aggregated average results - HOS diagram (Source: Authors’ elaboration, [11])

Table 5. The aggregate levels of the individual subsystems and the simple statistical diagnostics (Source: Authors' elaboration in the Maple system according to [11])

\begin{tabular}{ccccc}
\hline SUBSYSTEM & LEVEL & AVERAGE & VARIANCE & $\begin{array}{c}\text { STANDARD } \\
\text { DEVIATION }\end{array}$ \\
\hline HW & $\boldsymbol{L}_{\boldsymbol{1}}$ & 3.02 & 0.285 & 0.533 \\
\hline SW & $\boldsymbol{L}_{\mathbf{2}}$ & 3.15 & 0.334 & 0.578 \\
\hline OW & $\boldsymbol{L}_{\boldsymbol{3}}$ & 2.84 & 0.566 & 0.752 \\
\hline PW & $\boldsymbol{L}_{\mathbf{4}}$ & 2.94 & 0.401 & 0.633 \\
\hline DW & $\boldsymbol{L}_{5}$ & 3.15 & 0.371 & 0.609 \\
\hline CU & $\boldsymbol{L}_{\boldsymbol{6}}$ & 2.84 & 0.399 & 0.632 \\
\hline SU & $\boldsymbol{L}_{\boldsymbol{7}}$ & 2.90 & 0.292 & 0.540 \\
\hline MA & $\boldsymbol{L}_{\boldsymbol{8}}$ & 3.04 & 0.463 & 0.680 \\
\hline
\end{tabular}


Table 6. The aggregated overall and recommended levels of the subsystems and the simple statistical diagnostics (Source: Authors' elaboration in the Maple system according to [11])

\begin{tabular}{lccc}
\hline LEVEL IS & AVERAGE & VARIANCE & $\begin{array}{c}\text { STANDARD } \\
\text { DEVIATION }\end{array}$ \\
\hline Overall & 2.44 & 0.359 & 0.599 \\
\hline Recommended & 3.58 & 0.309 & 0.556 \\
\hline
\end{tabular}

Discussion: Let us summarize the results for the sample of the monitored organizations. From Figure 4, Table 5 and Table 6, by using the results analysis of the axes, we can see that:

- On any axis the aggregate levels do not show significant differences, i.e., each subsystem of the monitored information systems can be assessed as sufficiently harmonized (balanced);

- A regular dark grey octagon (smaller) presents the aggregate overall level of the monitored information systems (that is given by the perception of the importance of the information system in the organization) and its level is close to the value of 2.5 , the whole status of the IS can be identified between somewhat good and somewhat bad;

- An irregular light grey octagon (larger) indicates the level of the individual subsystems of the monitored information systems, and these levels move around the value of 3, i.e., somewhat good;

- The monitored information systems show the worst results (imbalance) in the subsystems of: OW - Orgware, MA - Management IS and CU - Customers (users).

\subsection{Aggregated Results as Related to Subsystems of the Information Society}

We can see a representation of the balanced / unbalanced / heavily unbalanced 425 monitored information systems, as related to the areas of the information society, see Figure 5.

Discussion: Based on the outputs we have identified by means the Zefis portal and the HOS method, we believe that:

- It is basically logical that in the category of the ICT Infrastructure there be a dominance of balanced IS. The large number of heavily unbalanced information systems seems astonishing.

- The proportion of balance / imbalance / heavy imbalance in the category of Education is similar. This not so good situation may be the result of frequent changes in this category.

- An interesting negative aspect is the comparable ratio of all three types of balanced / unbalanced / heavily unbalanced information systems in the category of Public Administration. These organizations have a unified environmental management system at their disposal - a result of the progression towards e-government in the CZ. The resulting proportions (balanced / unbalanced / heavily unbalanced IS) of organizations involved in our research are very unfavourable for this category. It is necessary to further analyse the reasons for this in detail. 


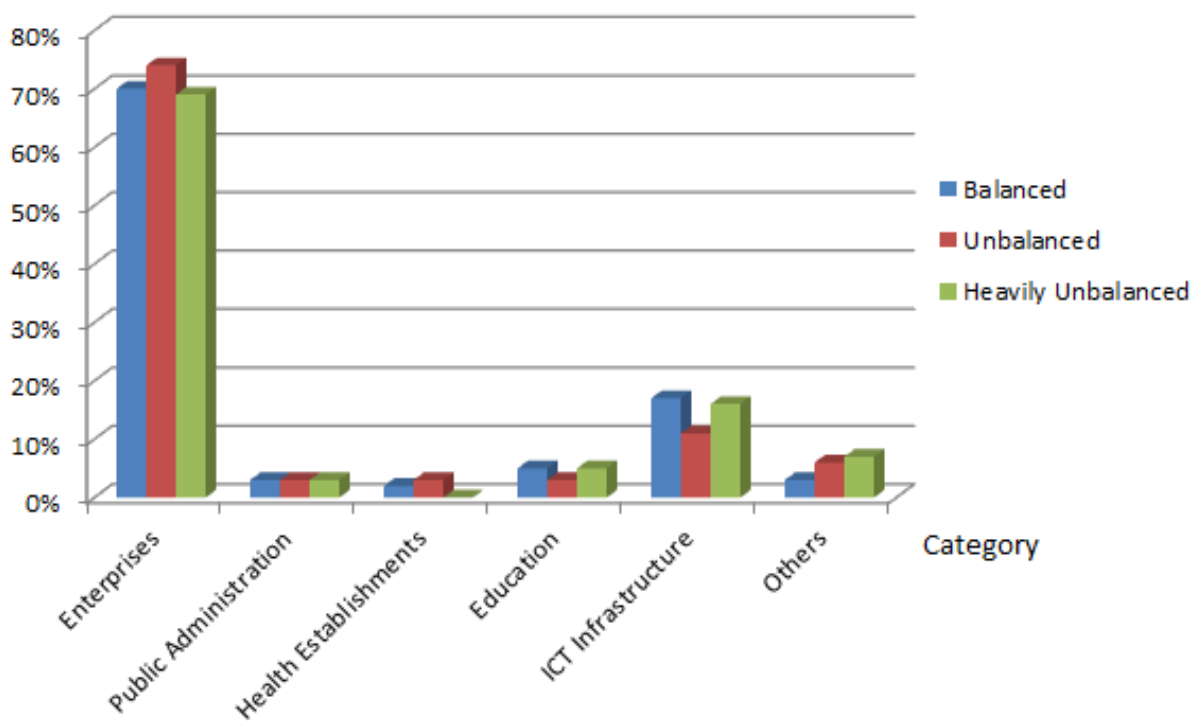

Fig. 5. IS evaluation as related to areas of the information society (Source: Authors' elaboration according to [11] in Microsoft Excel)

- The situation in the category of Enterprises is cause for concern. It can be estimated that many enterprises do not utilize their information systems effectively. It appears that the management of many enterprises place other values above an appropriate information system. Their activities can, however, have a significant impact on the environment.

- A partly good tendency (this is only due to the fact that the number of heavily unbalanced information systems is quite small) appears in the category of Health Establishments. We believe that this reason may be applied, as the number of unbalanced information systems is large enough.

- The situation in the category of Others which consists mainly of Households and Individuals can be attributed to poor professionalism. This may explain the rather negative proportions of balance / imbalance / heavy imbalance.

\subsection{Aggregated Results Regarding Number of Staff}

We can see a representation of the balanced / unbalanced / heavily unbalanced state of the 425 monitored information systems, as classified by the size of the organization, see Figure 6 (for each number of staff category separately) and Figure 7 (for the whole sample of monitored organizations). 


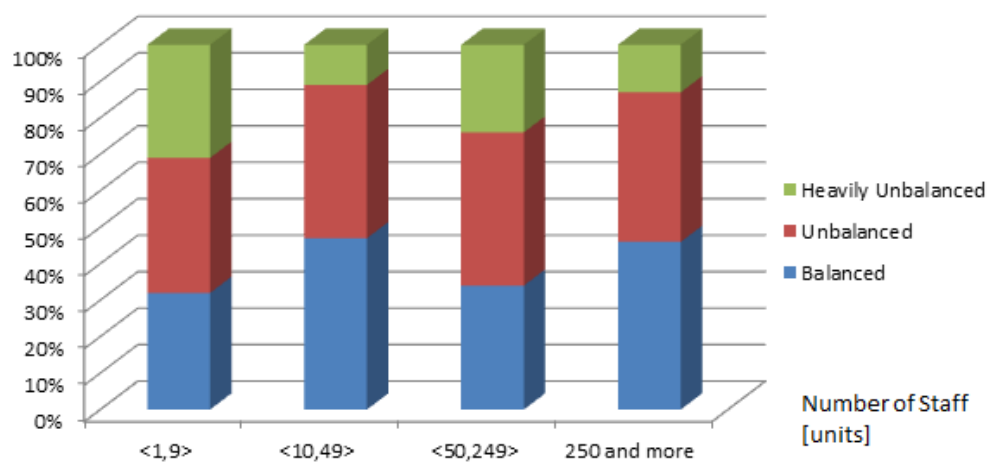

Fig. 6. IS evaluation by number of staff, for each organization separately (Source: Authors' elaboration according to [11] in Microsoft Excel)

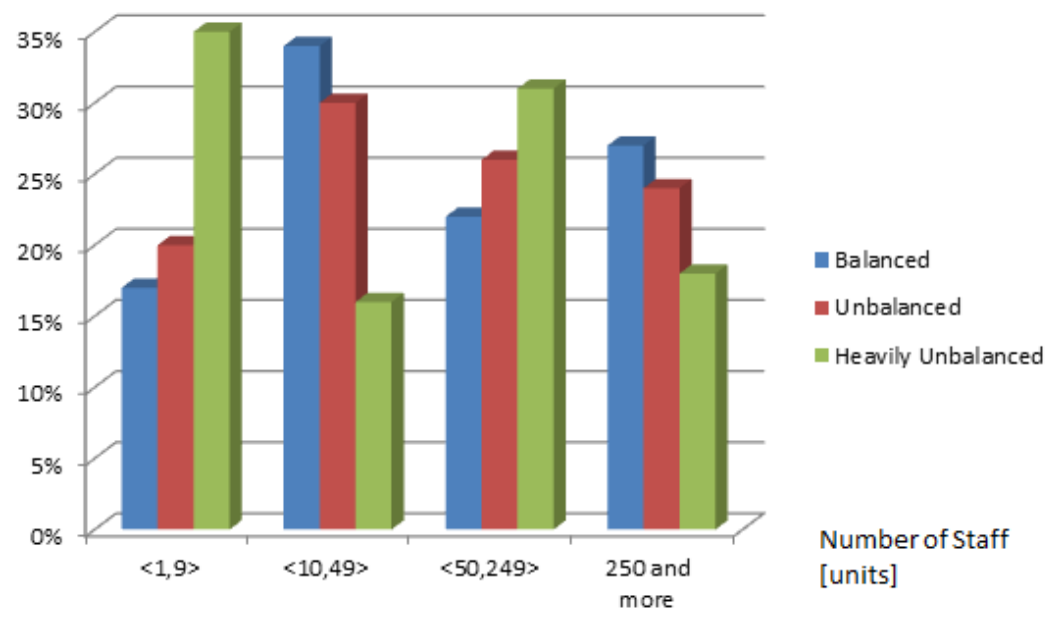

Fig. 7. IS evaluation by number of staff (Source: Authors' elaboration according to [11] in Microsoft Excel)

Discussion: Based on the outputs that we have identified by using the Zefis portal and the HOS method, we believe that:

- In the case of large organizations employing 250 and more people, the situation is good enough (except for very large organizations with over 1,000 employees, as it has turned out by using other, more detailed investigation methods). These organizations are probably beginning to manage their information systems. However, the scope of the systems is not so large, it can therefore still be rationally managed in a better way, and it can be adapted to changing conditions in a flexible manner. Note: Probably, for very large organizations (with more than 1,000 employees) we must begin to take into account the 'heaviness' of large systems that cannot be flexibly changed and readily adapted to individual requirements. 
- The explanation of this phenomenon requires further investigation. However if the obtained results are true, it shows that small organizations with 11 - 49 employees have already surpassed the amateur approach to the use information systems (which we can see in the case of micro-organizations). They operate on a relatively satisfactory level. This is due, among other factors, to a relatively small scale of information systems of small organizations. This allows them to rationally manage and use information systems without complicated methodologies, such as ITIL or COBIT. This may be a positive trend in terms of environmental protection.

\section{Conclusion}

The Zefis portal is designed for the evaluation of the efficiency of organizations' information systems. It uses the HOS method to provide an inclusion in one of the classes: balanced / unbalanced / heavily unbalanced IS. A balanced system supports the effectiveness of the IS. This classification is based on the evaluation of the eight subsystems of IS. The result is visualized in the HOS diagram, which also includes the recommended level, and the overall level of the IS. The survey captures the aggregate outputs relative to the monitored organizations. Our outcomes for the set of 425 monitored organizations are as follows:

The best results have been achieved by small organizations with $11-49$ employees. From this perspective, it also seems that organizations with $11-49$ employees have great potential in terms of impact on the environment. They usually operate in the local area, but they can help minimize the environmental burden on a national, and also on a global scale. Due to their size, they can work very effectively, and have an interest in the introduction of environmental supports, environmental information systems, environmental reporting, etc. The worst ratio of balanced and unbalanced systems is expected in the case of micro-small-organizations with a staff of less than 10. Medium-sized organizations (with the number of employees from 50 to 249) report worse results than large organizations (with the number of employees starting at 250). Note: In performing a deeper analysis, which is not the subject of this post, we have found, nevertheless, that very large organizations with 1,000 and more employees have worse results than organizations not exceeding 1,000 employees.

Obviously, the category of ICT Infrastructure has reached the best results in terms of balance. Negative findings in the category of Public Administration have obtained an approximately equal representation in all the three classes of balanced / unbalanced / heavily unbalanced IS. These organizations have a unified environmental management system at their disposal - as a part of the progression towards e-government in the CZ. It is relatively surprising that in the category of Enterprises it appears that many enterprises do not utilize their IS adequately and effectively. Currently, they should be supporting any activities (if they have not done so yet) leading to environmental protection, reporting (at least for the purpose of making a good name for the organization, for more competitiveness, a better market position, the creation of economic value, corporate performance, etc.). The situation is not very satisfactory in the categories of Education and Health Establishments. In these categories, we would expect a dominant balance that would support IS efficiency in the environmental field. The Others category is probably not very interesting as far as the efficiency of the organizations' IS is concerned. 
Acknowledgments. This paper is supported by The Czech Science Foundation. Name of the Project: Construction of Methods for Multifactor Assessment of Company Complex Performance in Selected Sectors. Reg. Nr. P403/11/2085.

\section{References}

1. Czech Statistical Office, http://www.czso.cz/

2. Dovrtěl, J.: Selected Aspects of the Effectiveness of Information Systems (Dissertation in Czech). BUT FBM, Brno (2004)

3. Gander, W., Hřebíček, J.: Solving Problems in Scientific Computing Using Maple and Matlab, 4th edn. Springer, Berlin (2004)

4. Hamilton, S., Chervany, N.L.: Evaluating Information Systems Effectiveness - Part II: Comparing Evaluator Viewpoints 5, 79-86 (1981)

5. Hřebíček, J., Kubásek, M.: Environmental Information Systems, 1st edn. CERM, Brno (2011) (in Czech)

6. Hilty, L., Page, B., Hřebíček, J.: Environmental Informatics. Environmental Modelling \& Software 21, 1517-1518 (2006)

7. Hodinka, M., Štencl, M., Hřebíček, J., Trenz, O.: Current Trends of Corporate Performance Reporting Tools and Methodology Design of Multifactor Measurement of Company Overall Performance. Acta Univ. Agric. et Silvic. Mendel. Brun. 60, 85-90 (2012)

8. Hřebíček, J., Pillmann, W.: eEnvironment: Reality and Challenges for eEnvironment Implementation in Europe. In: Hřebíček, J., Schimak, G., Denzer, R. (eds.) ISESS 2011. IFIP AICT, vol. 359, pp. 1-14. Springer, Heidelberg (2011)

9. Chvátalová, Z., Hřebíček, J.: Modeling and Simulation Utility Functions with Maple. Mendel Journal Series 1, 552-557 (2012)

10. Chvátalová, Z., Hřebíček, J.: Computational Finance and Finance Economics with Maple. International Journal of Mathematical Models and Methods in Applied Sciences 7, 541-550 (2013)

11. Koch, M.: ZEFIS: Online Assessment for your Information System. Brno (2013), http: / /www. zefis.cz/

12. Koch, M., Chvátalová, Z.: Information System Efficiency as an Attribute in Environmental Information Systems. In: Hřebíček, J., Schimak, G., Kubásek, M., Rizzoli, A. (eds.) ISESS 2013. IFIP AICT, vol. 413, pp. 31-43. Springer, Heidelberg (2013)

13. Ritschelová, I., Sidorov, E., Hřebíček, J.: Environmental Statistics at the CZSO: Past Development and Future Trends. In: Hřebíček, J., Schimak, G., Denzer, R. (eds.) ISESS 2011. IFIP AICT, vol. 359, pp. 33-46. Springer, Heidelberg (2011) 